\title{
Mechanized recovery of olive pruning residues: ash contamination and harvesting losses
}

\author{
A. Assirelli, ${ }^{1}$ A. Acampora, ${ }^{1}$ S. Croce, ${ }^{1}$ R. Spinelli, ${ }^{2}$ E. Santangelo, ${ }^{1}$ L. Pari ${ }^{1}$ \\ ${ }^{1}$ Consiglio per la ricerca e la sperimentazione in agricoltura, Unità di Ricerca per l'Ingegneria \\ Agraria, Monterotondo (Roma), Italy; ${ }^{2}$ CNR IVALSA, Sesto Fiorentino, Firenze, Italy
}

\begin{abstract}
Agricultural residues represent an important source of biomass for energy. Among the available biomass suitable for energy and available in Italy, pruning represents about the $20 \%$ of the total. About 1.184 million of hectares are planted with olive trees; the pruning residues coming from these plantations represent a wide source of biomass at National level. The authors tested six commercial pruning harvesters to determine harvesting losses and product contamination when recovering pruning residues. All harvesters used a mechanical pick-up to collect the residues and a shredder to reduce them into chips. Three different pick-up settings were tested and namely: $1 \mathrm{~cm}$ above ground level, manufacturer's specification and $3 \mathrm{~cm}$ above ground level. Ash content in the shredded material was taken as a measure of contamination: the uncontaminated branch material collected directly from the trees had a value of $3.5 \%$, whereas in shredded residues varied between $4.5 \%$ and over $5.5 \%$, for the shortest and the longest distance between the pick-up and the soil surface, respectively. Harvesting losses were slightly, but significantly, related to pick-up setting, and mainly depended on machine type. Both machines have shown a good quality of the work performed and the results obtained indicates that the work phases could be simplified in order to reduce both the time of use and the harvesting costs.
\end{abstract}

\section{Introduction}

Biomass represents the fourth largest source of energy (after coal, oil

Correspondence: A. Assirelli, CRA - ING, via della Pascolare 16, 00016 Monterotondo (RM), Italy.

Tel. +39.06 .90675211 - Fax: +39.06 .90625591$

E-mail: alberto.assirelli@entecra.it

Key words: biomass, energy, wood, particle size, ash, shredding.

Acknowledgments: the authors would like to thank the role of the "FAESI" Project (Filiere Agro Energetiche nel Sud Italia) for funding the study.

(C) Copyright A. Assirelli et al., 2013

Licensee PAGEPress, Italy

Journal of Agricultural Engineering 2013; XLIV(s2):e123

doi:10.4081/jae.2013.s2.e123

This article is distributed under the terms of the Creative Commons Attribution Noncommercial License (by-nc 3.0) which permits any noncommercial use, distribution, and reproduction in any medium, provided the original author(s) and source are credited. and natural gas) and already satisfies about 14\% of the energy needs of human society (Parikka, 2004). Large amounts of wood biomass can be obtained from pruning of fruit orchards in the Mediterranean region (FAO, 1997). In Italy, olive groves cover about 1.1 million of hectares, of which about one-third are located in southeastern Italy (Istat, 2001). In Puglia region, these orchards could yield over 800,000 tonnes of dry biomass per year. Nevertheless, the current practice is to dispose of pruning residues through burning or mulching, with no direct economic benefit (Askew and Holmes, 2001). However, research has intensified in recent years, drawing more attention on pruning residue as a possible source of energy (Dalla Marta et al., 2010; Masera et al., 2006). More specifically, several studies have confirmed that agricultural residues may be a suitable source of biomass for the production of thermal and electrical energy (Caputo et al., 2003; Kuiper et al., 1998; Malaspina et al., 1996; Mussatto et al., 2006).

The market offers today various types of machines dedicated to the recovery of pruning residues and their conversion into a biomass product (Magagnotti et al., 2013; Recchia et al., 2009). These implements have received considerable interest and their performances have been documented in several studies, especially concerning the productivity and cost. Much less is known about harvesting losses and product contamination, above all when working on olive orchards (Spinelli et al., 2012; Spinelli et a l., 2010). Losses and contamination are probably related, and may in part depend on the machine settings. Losses can be reduced by lowering the pickup device, in order to catch the residues closer to the ground. Moreover, working too close to the ground product may increase soil contamination with soil particles.

The purpose of this study was to determine harvesting losses and product contamination achieved with six commercial machines, under three different settings: standard pick-up height as conventionally set by the manufacturer; pick-up working $1 \mathrm{~cm}$ above ground level; pick-up working $3 \mathrm{~cm}$ above ground level.

\section{Material and methods}

The work took place in Castrigliano de' Greci, southeastern Italy $\left(40^{\circ} 10^{\prime} 32^{\prime \prime}\right.$ North, $18^{\circ} 19^{\prime} 11^{\prime \prime}$ East). The testing area was a 0.45 ha olive tree plantation, 40 years old and established at a $7.5 \times 7 \mathrm{~m} \mathrm{spac}$ ing. Trees had not been pruned for several years, leading to a very large residue yield. Six commercial shredding units were compared and for each (Table 1) three different pick-up settings were considered: standard height set by the manufacturer (setting B); working height $1 \mathrm{~cm}$ above ground level (setting A); working height $3 \mathrm{~cm}$ above ground level (setting $\mathrm{C}$ ). Each treatment was replicated three times for each machine, for a total of 54 replications.

In order to evaluate the yield of pruning residues, 12 test windrow were analyzed:

all the residues present in 48 sample areas (1 x $1.5 \mathrm{~m}$ ) randomly selected has been collected and weighed. Residue was character- 
ized by measuring the diameter and length of individual branches in the sample plots. Harvesting losses were estimated by repeating the same procedure after sampling, this time on 4 sample plots per machine and setting (72 samples). The moisture content was determined on three $250 \mathrm{~g}$ samples per plot, according to European standards UNI-EN 14774-1: 2009. Ash content was taken as a measure of contamination and determined on $1.5 \mathrm{~kg}$ samples, according to European standard CEN/TS 14775: 2010. Three samples were collected directly from the branches before harvesting, in order to determine a reference ash content before the eventual contamination caused by recovery. Three samples for each treatment (54 samples) were collected from the shredded material accumulated on the sideline.

The study has included the particle size distribution and bulk density. These parameters were determined for one settings only, hypothesizing that product size and density depend by machine characteristics and not by pick-up settings. Bulk density was determined according to European standard UNI-EN 15103: 2009. Particle size distribution was determined on four 4-L samples per machine. Each sample was weighed and the material was divided in three dimensional classes $(<5 \mathrm{~cm}$, among $5 \mathrm{~cm}$ and $10 \mathrm{~cm},>10 \mathrm{~cm})$. These dimensional classes were weighed again for defining the percent incidence of each class on total sample weight.

The distribution of the data collected was plotted and checked for normality. If complying with normality, the differences between the treatments were tested using analysis of variance. When the data distribution did not accord to normality, the arcsine transformation was used for their normalization. The data were analyzed statistically using Statview for Windows.

\section{Results}

All test machines adopted the same working principles. Differences were mainly in some structural details, such as the number of teeth on the pick-up device, or of hammers on the shredder.

The overall amount of pruning residues detected was equal to 14 green tons per hectare. Moisture content at harvest was $22 \%$, defining a good quality fuel. The six tested machines have given a different shredde d product, in terms of particle size distribution (Figure 1) and bulk density (Table 2). The Berti and Omat harvesters produced a larger amount of oversize material compared to all other machines, while the Sgarbi, Tierre and the Facma harvesters made much smaller particles, with a low proportion of oversize elements and a high incidence of fines. The length of the shredded material is important for the feeding system of the boilers because, if employing screw systems, a product with particles greater than $10 \mathrm{~cm}$ can determine problems of flooding or blockages in the system.

As shown in the table 2, the bulk density of the shredded product was significantly higher for the Sgarbi and the Nobili shredder. The higher value of bulk density relative to the product of the Nobili machine could be ju stified because the TPR-CV 145 is the only tested model equipped with a system that discharge the chips, at high pressure, in a specific trailer that follows the machine along the working line during the field operations. Respect to the systems used by the other machines, which present their own collection bin, the high pres-

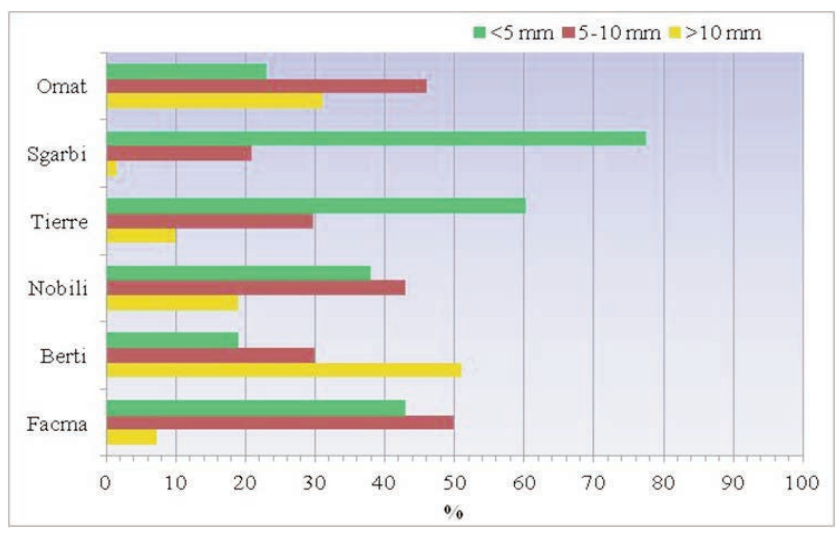

Figure 1. particle size distribution (\%) of the shredded olive pruning residues.

Table 1: characteristics of the tested machines.

\begin{tabular}{lcccccc} 
Make & Tierre & Omat & Nobili & Sgarbi & Facma \\
Model & Futura 160 & TSB 1900 & TRP-CV 145 & TR-RAC & Comby TR 200 Piker-Kargo 200 \\
Work width & 1.566 & 1.900 & 1.450 & 1.996 & 1.995 & 2.000 \\
\hline Diameter pick-up cylinder & 127 & 140 & 153 & Na & 95 & 127 \\
Teeth on pick-up & 38 & 42 & 32 & Na & 72 & 33 \\
\hline Teeth lengh & 159 & 170 & 156 & Na & 160 & 150 \\
Distance between teeth & 72 & 170 & 170 & Na & 100 & 60 \\
\hline Diameter of shredder (mm) & 193 & 480 & 465 & 168 & 229 & 410 \\
Hammers on shredder (n) & 28 & 22 & 20 & 20 & 27 & 36 \\
\hline
\end{tabular}

Table 2: bulk density of the shredded olive pruning residues.

\begin{tabular}{lccccccc} 
& Tierre & Omat & Nobill & Sgarbi & Facma & Berti \\
Bulk density (Kg m-3) & 128 & 119 & 174 & 158 & 134 & 124 \\
\hline
\end{tabular}


sure system of the TPR-CV 145 could determine a higher compaction of the shredded product in the trailer. That would explain the higher quantity of product per m3.

The Sgarbi machine produced relatively dense loads, which was likely due to the virtual absence of oversize particles ( $>10 \mathrm{~cm}$ long). In contrast, long fragments tended to structure, increasing the bulk volume of loads (Jensen et al., 2004).

Percent harvesting losses were very low but comparable to those reported in previous studies (Magagnotti et al., 2013). Mean harvesting losses varied from 0.4 to $6 \%$ (Table 3 ), and were significantly related to both machine type and pick-up settings (Table 4). Losses were lowest for the Berti, Omat an d Facma harvesters, and highest for the Nobili, Sgarbi and Tierre machines. Machine type had a much stronger effect on losses than pick-up setting. Pick-up teeth number and length were both tested as additional factors in determining harvesting losses, but they did not result to have any significant effect. Attention was then directed to work width, since two of the machines incurring the highest loss es also had a reduced work width. It is conceivable that a main cause for high losses could be the mismatch between windrow width and machine work width. In fact, narrower harvesters may have missed the residues placed at the windrow edges. When pruning yield is elevated is difficult to build the narrow swaths, in these conditions the machines should offer the largest possible work width.

Pruning resid ue was contaminated during recovery, as indicated by the higher ash content of shredded material compared to branch material collected directly from the trees. Mean ash content for the uncon- taminated branch material was 3.5\%, and was significantly lower compared to all other treatments. Ash content ranged from an minimum of $4 \%$ to a maximum of $6 \%$. Mean values varied between $4.6 \%$ and $5.7 \%$ (Table 5). Ash content was significantly associated to both machine type and pick-up settings, this one having the strongest effect (Table 4). Raising pick-up height to $3 \mathrm{~cm}$ above ground level allowed reducing ash content by up to $1 \%$ point, compared to working with the pick-up at $1 \mathrm{~cm}$ above ground level.

Contamination was effectively reduced by increasing the distance between the pick-up device and the soil surface. Increasing pick-up height also resulted in an increase of harvesting losses, but the effect of pick-up setting on product recovery was much lower than the effect of machine design. In contrast, machine design only had a secondary effect on contamination.

\section{Conclusions}

Numerous studies have demonstrated that it is possible to recover and utilize pruning for the production of energy, ensuring economic and environmental sustainability of the supply chain. Regular pruning of olive groves generates large amounts of wood biomass, which can be recovered and processed with commercial pruning harvesters.

Effective recovery implies minimizing product losses and product contamination. The former is mainly related to machine type, the latter to pick-up setting. Product losses might be reduced by selecting
Table 3: harvesting losses (\%) as a function of machine type and a pick-up setting (arcsine).

\begin{tabular}{|c|c|c|c|}
\hline & \multicolumn{3}{|c|}{ Height setting } \\
\hline & A & B & C \\
\hline Tierre & 2.09 & 3.05 & 4.01 \\
\hline Omat & 0.8 & 1.1 & 1.6 \\
\hline Nobili & 3.2 & 3.9 & 4.2 \\
\hline Sgarbi & 4,6 & 5.4 & 6 \\
\hline Facma & 1 & 1.3 & 1.9 \\
\hline Berti & 0.4 & 0.6 & 0.9 \\
\hline
\end{tabular}

Table 5: percent ash content as a function of machine type and pick-up height setting.

\begin{tabular}{lccc} 
& \multicolumn{3}{c}{ Height setting } \\
Tierre & B & C \\
Omat & 5.2 & 4.8 & 4.7 \\
\hline Nobili & Na & 4.4 & Na \\
Sgarbi & 5.7 & 5.3 & 4.6 \\
\hline Facma & 5.2 & 4.8 & 4.9 \\
Berti & 5.1 & 5 & 4.9 \\
\hline
\end{tabular}

Table 4: result of the analysis of variance for harvesting loss and ash content.

\begin{tabular}{|c|c|c|c|c|c|c|}
\hline Effect & DF & SS & $\%$ & F-value & P-value & Power \\
\hline \multicolumn{7}{|c|}{ Harvesting loss } \\
\hline Setting & 2 & 0.014 & 5.9 & 188.18 & $<0.0001$ & 1.00 \\
\hline Machine & 5 & 0.22 & 93.1 & 1225.12 & $<0.0001$ & 1.00 \\
\hline Interaction & 10 & $2.79 * 10-4$ & 0.1 & 0.78 & 0.6496 & 0.36 \\
\hline Residual & 54 & 0.002 & 0.8 & & & \\
\hline \multicolumn{7}{|l|}{ Ash content } \\
\hline Setting & 2 & 3.292 & 43.4 & 26.27 & $<0.0001$ & 1.00 \\
\hline Machine & 4 & 0.677 & 8.9 & 2.7 & 0.0493 & 0.68 \\
\hline Interaction & 8 & 1.739 & 22.9 & 3.47 & 0.006 & 94.00 \\
\hline Residual & 30 & 1.88 & 24.8 & & & \\
\hline
\end{tabular}

for the harvesting loss, the analysis was conducted on arcsine-transformed data; $\%=$ incidence of the sum of squares for the individual effect over the total Sum of Squares. 
appropriate equipment, offering a good match between work width and expected windrow width. The lowering of contamination level can be achieved by increasing the distance between the soil surface and the machine pick-up, to avoid raking into the soil.

\section{References}

Askew M.F., Holmes C. The potential for biomass and energy crops in agriculture in Europe, in land use, policy and rural economy terms. Aspects Appl Biol 2001; 65: 365-374.

Caputo A., Scacchia F., Pelagagge P. Disposal of by-products on olive oil industry: waste-to-energy solutions. Appl Therm Eng 2003; 23: 197214.

Dalla Marta A., Mancini M., Ferrise R., Bindi M., Orlandini S. Energy crops for biofuel production: analysis of the potential in Tuscany. Biomass Bioenerg 2010; 34: 1041-1052.

FAO. The role of wood energy in Europe and OECD, WETT e wood energy today for tomorrow. Rome: FOPW, Forestry Department; 1997.

ISTAT. V. Censimento Generale dell'Agricoltura. Roma; 2001.

Jensen P., Mattsson J.E., Kofman P.D., Klausner A. Tendency of wood fuels from whole trees, logging residues and roundwood to bridge over openings. Biomass Bioenerg 2004; 26: 107-113.

Kuiper L., Sikkema R., Stolp J. Establishment needs for short rotation forestry in the EU to meet the goals of the commission's white paper on renewable energy. Biomass Bioenerg 1998; 15: 451-456.

Magagnotti N., Pari L., Picchi G., Spinelli R. Technology alternatives for tapping the pruning residue resource. Bioresour Technol 2013; 128: 697-702.

Malaspina F., Cellamare C., Sante L., Tilche A. Anaerobic treatment of cheese whey with a downflow- upflow hybrid reactor. Bioresour Technol 1996; 55: 131-139.

Masera 0., Ghilardi A., Drigo R., Trossero M. WISD0M: a GIS-based supply demand mapping tool for wood fuel management. Biomass Bioenerg 2006; 30: 618-637.

Mussatto S., Dragone G., Roberto I. Brewers' spent grain: generation, characteristics and potential applications. J Cereal Sci 2006; 43: 114.

Parikka M. Global biomass fuel resources. Biomass Bioenerg 2004; 27 : 613-620.

Recchia L., Daou M., Rimediotti M., Cini E., Vieri M. New shredding machine for re cycling pruning residuals. Biomass Bioenerg 2009; 33: 149-154.

Spinelli R., Picchi G. Industrial harvesting of olive tree pruning residue for energy biomass. Bioresour Technol 2010; 101: 730-735.

Spinelli R., Nati C., Pari L., Mescalchin E., Magagnotti N. Production and quality of biomass fuels from mechanized collection and processing of vineyard pruning residues. Appl Energ 2012; 89: 374-379. 